\title{
Fenologia reprodutiva da pitaya vermelha em Jaboticabal, SP
}

\author{
Reproductive phenology of red dragon fruit in Jaboticabal, SP, Brazil
}

\author{
Adriana de Castro Correia da Silva ${ }^{I}$ Ludmilla de Lima Cavallari ${ }^{\text {II }}$ Rafael Roveri Sabião ${ }^{\text {III }}$ \\ Antonio Baldo Geraldo Martins ${ }^{\text {III }}$
}

\section{RESUMO}

Por ser uma cultura de cultivo recente no país, a pitaya (Hylocereus undatus) ainda carece de estudos, de forma a dar suporte aos produtores. Nesse sentido, o trabalho foi desenvolvido visando a caracterizar a fenologia reprodutiva da cultura na região de Jaboticabal - SP. Avaliou-se clone de pitaya conduzido sob duas colorações de tela plástica, branca e preta, ambas com 50\% de sombreamento, durante março de 2009 a dezembro de 2010. Observou-se que a emissão de gemas florais tem início no mês de novembro, com emissão constante até o mês de março, enquanto que o florescimento ocorre até meados de abril, sendo que as altas temperaturas associadas ao início da estação chuvosa são fatores fundamentais para a emissão das gemas reprodutivas. A coloração da tela plástica influenciou no total de flores. O tempo compreendido desde a emissão das gemas até a antese é de 18 a 23 dias, enquanto, da antese à colheita é de 34 a 43 dias. $O$ tempo total entre o aparecimento do botão floral até a colheita pode levar de 52 a 66 dias.

Palavras-chave: Hylocereus undatus, comportamento fenológico, sombreamento.

\section{ABSTRACT}

The dragon fruit (Hylocereus undatus) is recent crop cultivation in Brazil and there is still lack of studies to support the farmers. So, this research aimed to characterize the reproductive phenology of the crop in the region of Jaboticabal, São Paulo State, Brazil. It was evaluated red dragon fruit clones over two environmental conditions - under plastic screen black and white, with 50\% of shady level, from March 2009 to December 2010. It was observed that the issuance of floral buds and the flowering on dragon fruit culture occurs with a combination of high temperatures and rainfall, with constant emission of floral buds from November to March while the flowering on dragon fruit culture occurs until mid-April. The color of plastic screen had influenced on amount of flowers. The time elapsed since the issuance of flower buds to anthesis is from 18 to 23 days, while the harvest occurs from 34 to 43 days after flower opening. At Jaboticabal, the time of appearance of flower bud to fruit harvest is from 52 to 66 days.

Key words: Hylocereus undatus, phenology, shady.

\section{INTRODUÇÃO}

A pitaya vermelha [Hylocereus undatus (Haworth) Britton \& Rose] é uma cactácea nativa da América Latina, provavelmente do México e Colômbia, sendo hoje amplamente distribuída por todo o mundo nas regiões tropicais e subtropicais (LE BELLEC et al., 2006). No Brasil, seu cultivo ainda é incipiente, existindo pequenas áreas de produção situadas principalmente no Estado de São Paulo, localizadas na região de Catanduva (BASTOS et al., 2006).

Para seu cultivo, é indicado que a planta seja conduzida sob condições de sombreamento entre 30 a $60 \%$, dependendo do local (MIZRAHI \& NERD, 1999), pois sua atividade fotossintética e seu crescimento são inibidos quando cultivada a pleno sol (RAVEH et al., 1998), ocorrendo o amarelecimento dos cladódios (RAVEH et al., 1993). Porém, o

\footnotetext{
IAgência de Desenvolvimento Agrário e Extensão Rural (AGRAER), Rod. BR 080, km 10, 79114-005, Campo Grande, MS, Brasil. E-mail: correiadasilva@yahoo.com.br. Autor para correspondência.

IIInstituto de Ensino Superior de Ariquemes, Ariquemes, RO, Brasil.

IIIDepartamento de Produção Vegetal, Faculdade de Ciências Agrárias e Veterinárias de Jaboticabal (FCAV), Universidade Estadual Paulista "Júlio de Mesquita Filho" (UNESP), Jaboticabal, SP, Brasil. 
sombreamento excessivo também pode prejudicar seu desenvolvimento, resultando em estiolamento de cladódios e severa redução do florescimento, consequentemente, afetando a produção (MERTEN, 2003). Assim, é essencial compreender as possíveis interações entre o florescimento e os fatores ambientais para maximizar a produção de frutos. A indução de floração está ligada a atributos da planta e do ambiente. Em relação à planta, a idade e tamanho são fundamentais para algumas espécies. Fotoperíodo e temperatura destacamse na ecofisiologia do florescimento (TAIZ \& ZEIGER, 2009). A pitaya é uma espécie dependente do fotoperíodo, sendo caracterizada como de dias longos (NERD et al., 2002a).

O conhecimento da fenologia reprodutiva de uma determinada frutífera é importante, pois as informações obtidas sobre os períodos de brotação, florescimento, frutificação e colheita podem auxiliar no estabelecimento de tratos culturais e fitossanitários mais adequados (MARO et al., 2012; OLIVEIRA et al., 2012). Diante do exposto, o objetivo deste trabalho consistiu em avaliar a fenologia reprodutiva de plantas de pitaya vermelha, em dois ciclos de produção, com sombreamento com duas colorações de telas, na região de Jaboticabal, SP.

\section{MATERIAL E MÉTODOS}

O trabalho foi desenvolvido em área experimental do Departamento de Produção Vegetal da Faculdade de Ciências Agrárias e Veterinárias - UNESP - Campus de Jaboticabal - SP. O local apresenta solo do tipo LATOSSOLO VERMELHO eutroférrico, A moderado, textura argilosa, segundo classificação da EMBRAPA (1999). O clima da região, segundo a classificação de Köppen, é Cwa (subtropical, com inverno seco e verão chuvoso), apresentando temperatura média anual de $22^{\circ} \mathrm{C}$.

Avaliou-se clone de pitaya vermelha $[\boldsymbol{H}$. undatus (Haworth) Britton \& Rose] proveniente de mudas produzidas por meio de estacas e implantadas na área experimental em 2003. As plantas estão sendo cultivadas tutoradas em mourão de eucalipto, sob cobertura de tela plástica, com $50 \%$ de sombreamento, que cobre apenas a parte superior da planta, evitando exposição direta ao sol no período mais quente do dia.

Inicialmente, para instalação do experimento, as plantas foram previamente podadas, reduzindo-se o tamanho do ramo, para que houvesse padronização do seu comprimento. Após a poda, em cada planta, foram marcados três cladódios, sadios, distribuídos ao acaso, na parte mediana da planta, sem a presença de gemas ou frutos, onde foi avaliado o número de gemas floríferas, de flores e de frutos emitidos a cada ciclo. As avaliações foram realizadas a cada três dias, em 40 plantas, sendo vinte sob cobertura de tela plástica branca (clarite ${ }^{\circledR}$ ) e 20 sob cobertura de tela plástica preta (sombrite ${ }^{\circledR}$ ), no período de março de 2009 a dezembro de 2010. Foi caracterizada a duração, em dias, dos seguintes estádios: emissão das gemas, desenvolvimento do botão floral, florescimento, desenvolvimento de frutos, início da maturação e colheita. Para caracterização do desenvolvimento dos frutos, foram realizadas polinizações manuais, em virtude da falta de polinizadores eficientes e da incompatibilidade polínica observada no clone avaliado. Na ocasião da antese, as flores foram emasculadas e polinizadas com pólen coletado de flores de $\boldsymbol{H}$. polyrhizus. Após a polinização, as flores foram cobertas com sacos plásticos do tipo TNT (tecido não tecido), mantidos por cerca de dez dias, sendo retirados quando foi verificado o pegamento, constatado pelo inchaço do ovário.

\section{RESULTADOS E DICUSSÃO}

A emissão das gemas reprodutivas no ano de 2009 ocorreu no início do mês de novembro, enquanto que, em 2010, houve um atraso de cerca de 15 dias, havendo a emissão das gemas posteriormente à segunda quinzena do mês. Apesar de não se ter variações climáticas que possam justificar este comportamento, é de se supor que pequenas mudanças de temperatura ou luminosidade influenciem esta característica. Antes que ocorresse a antese das primeiras flores, ocorreu a emissão de novas gemas floríferas. Assim, podem-se encontrar plantas com botões florais desenvolvidos, flores abertas, frutos e novas gemas. Este comportamento mostra que a planta possui múltiplas demandas nessa fase, devido ao aumento da relação fonte/dreno. Assim, é necessário que os produtores deem maior atenção a este período, pois pode ser considerado o de maior exigência da planta, no que se refere à irrigação e adubação, além da competição entre os frutos nos diversos estádios de desenvolvimento, indicando que a realização de desbaste é uma prática que deve ser considerada para a obtenção de frutos comercializáveis. É importante também atentar quanto à aplicação de defensivos, uma vez que pode afetar a presença de polinizadores e também quanto ao resíduo nos frutos, uma vez que podem ser encontrados, na mesma planta, em diversas fases de desenvolvimento. 
$\mathrm{Na}$ região de Jaboticabal - SP pode-se observar a ocorrência de nove fluxos floríferos anuais. O primeiro florescimento ocorreu em novembro, havendo florescimentos sucessivos até meados de abril. Em Lavras - MG, o florescimento da pitaya se dá em três a cinco surtos de floradas (MARQUES et al., 2011), entre novembro a março, enquanto que, em Israel, o florescimento de $\boldsymbol{H}$. undatus, $\boldsymbol{H}$. polyrhizus e $\boldsymbol{H}$. costaricensis (estas duas últimas espécies de polpa roxa) ocorrem em dois ou três fluxos durante o verão (WEISS et al., 1994). NERD et al. (2002), também em trabalho realizado em Israel, observaram que o florescimento de $\boldsymbol{H}$. undatus e $\boldsymbol{H}$. polyrhizus, nas zonas costeiras, ocorreu no verão e outono, com três ou quatro fluxos, enquanto nas regiões de vale foi restrito ao outono, com um pequeno fluxo (menos que cinco flores por metro linear). Estes autores observaram que as altas temperaturas que prevalecem nos vales inibem a produção de flores em ambas as espécies estudadas.

A emissão de gemas predominou em novembro, nos dois ciclos de produção avaliados, com cerca de $35 \%$ do total emitido durante o período de novembro a março, quando houve a menor quantidade emitida ( $8 \%$ do total). No mês de dezembro, ocorreu a abertura da maior quantidade de flores $(30 \%)$, em reflexo do desenvolvimento da maior quantidade de botões florais emitidos durante o mês anterior.
Observou-se que a emissão de gemas coincidiu com altas temperaturas e início da estação chuvosa (Figura 1). Este resultado é semelhante ao relatado por MARQUES et al. (2011) em Lavras, MG, onde o florescimento da pitaya vermelha também tem início no verão. $\mathrm{O}$ desenvolvimento de frutos associados ao período chuvoso também foi relatado para outras cactáceas, como Stenocereus stellatus (Pfeiff.) Riccob (GARCÍA-SUÁREZ et al., 2007), Pilosocereus sp., Cereus hexagonus (L.) Mill (RUIZ et al., 2000) e Opuntia ficus-indica (L.) Mill. (SEGANTINI et al., 2010). O desenvolvimento florífero em época chuvosa pode ser prejudicial à porcentagem de fixação de frutos, já que a flor abre apenas uma vez. Caso ocorra precipitação na noite da abertura, pode ocorrer lavagem do grão de pólen, o que inviabiliza a polinização, resultando em queda da produção. Além disso, nessas condições, a ocorrência de doenças se acentua, aumentando o custo pelo aumento do número de pulverizações ou perda de qualidade.

Nos diferentes fluxos e épocas avaliadas, o florescimento ocorreu entre 18 e 23 dias após o surgimento da gema florífera, concordando com NERD et al. (2002), que afirmam que o desenvolvimento da gema, até a antese, é de cerca de três semanas. Na região de Lavras, MG, o florescimento ocorre entre 19 a 21 dias após a emissão das gemas (MARQUES et al., 2011). A abertura

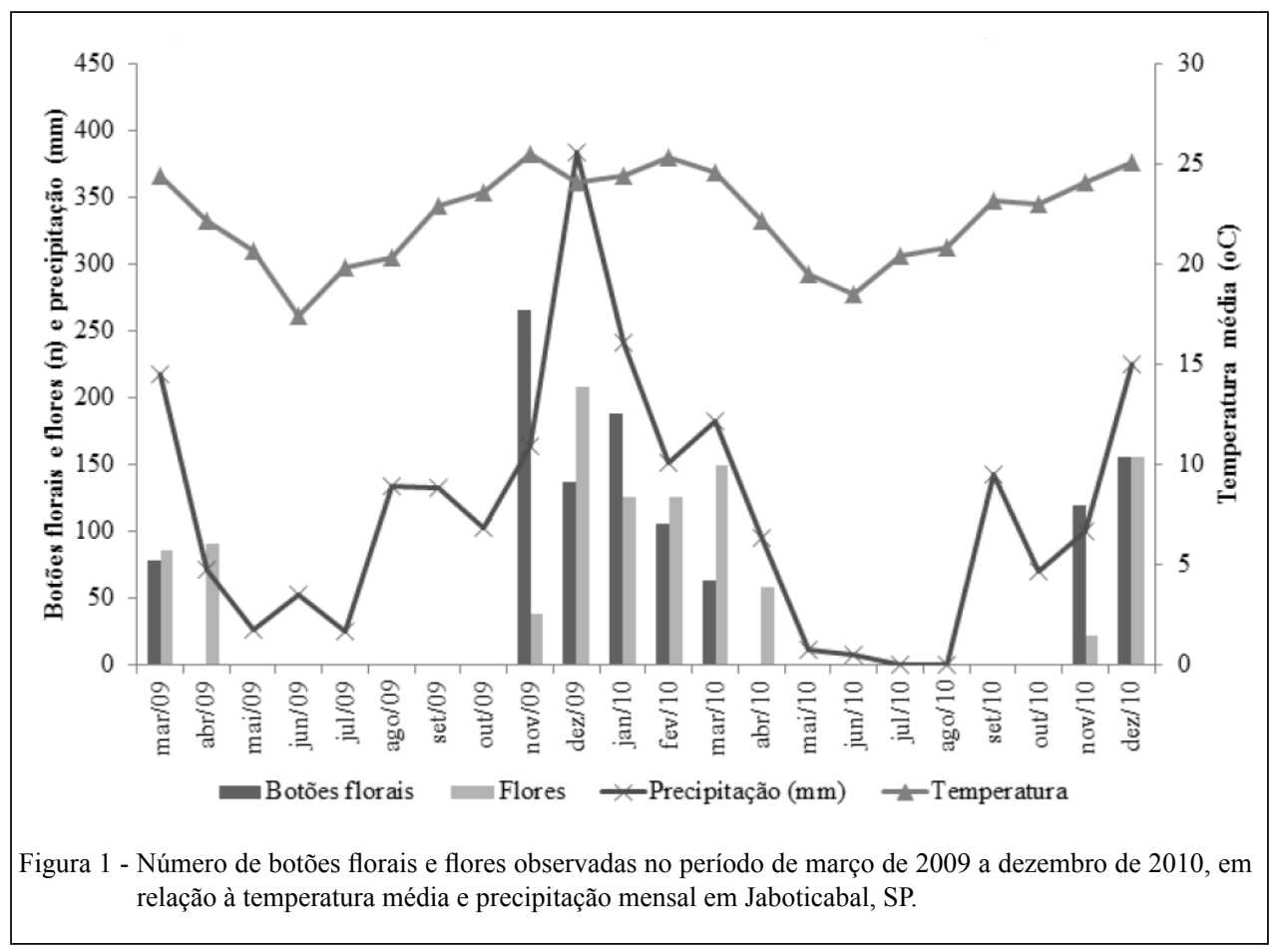

Ciência Rural, v.45, n.4, abr, 2015. 
floral ocorreu no início da noite, com fechamento na manhã seguinte, sendo que, em dias nublados, ela se estende até quase o fim da manhã. Na literatura, é relatado que morcegos, mariposas e abelhas (VALIENT-BANUET et al., 2007; MARQUES et al., 2012) são polinizadores naturais das pitayas. No Brasil, é relatado que apenas as abelhas atuam como polinizadores desta espécie (MARQUES et al., 2012) e, devido ao seu tamanho, são muito menos eficientes que os morcegos (VALIENTE-BANUET et al., 2007), além de atuarem num período menor de abertura das flores, uma vez que o fechamento destas ocorre logo pela manhã. Assim, a polinização manual torna-se uma prática necessária para a obtenção de frutos comerciais.
O sombreamento afetou a formação e a produção de flores (Figura 2). Observou-se maior emissão de botões florais (15\% a mais) nas plantas conduzidas sob tela plástica preta, em relação ao total de botões emitidos pelas plantas conduzidas sob tela plástica branca. Porém, a porcentagem de botões que floresceram foi semelhante, cerca de $87 \%$ do total nos dois ambientes, mas com $13 \%$ a mais de produção sob tela escura. BEZERRA NETO et al. (2005) relatam que o tipo de radiação que chega à superfície foliar é variável com a coloração da tela de sombreamento, sendo que o teor de radiação fotossinteticamente ativa é maior sob a tela branca em relação à tela preta. Além disso, as diferentes colorações de tela podem acarretar num pequeno

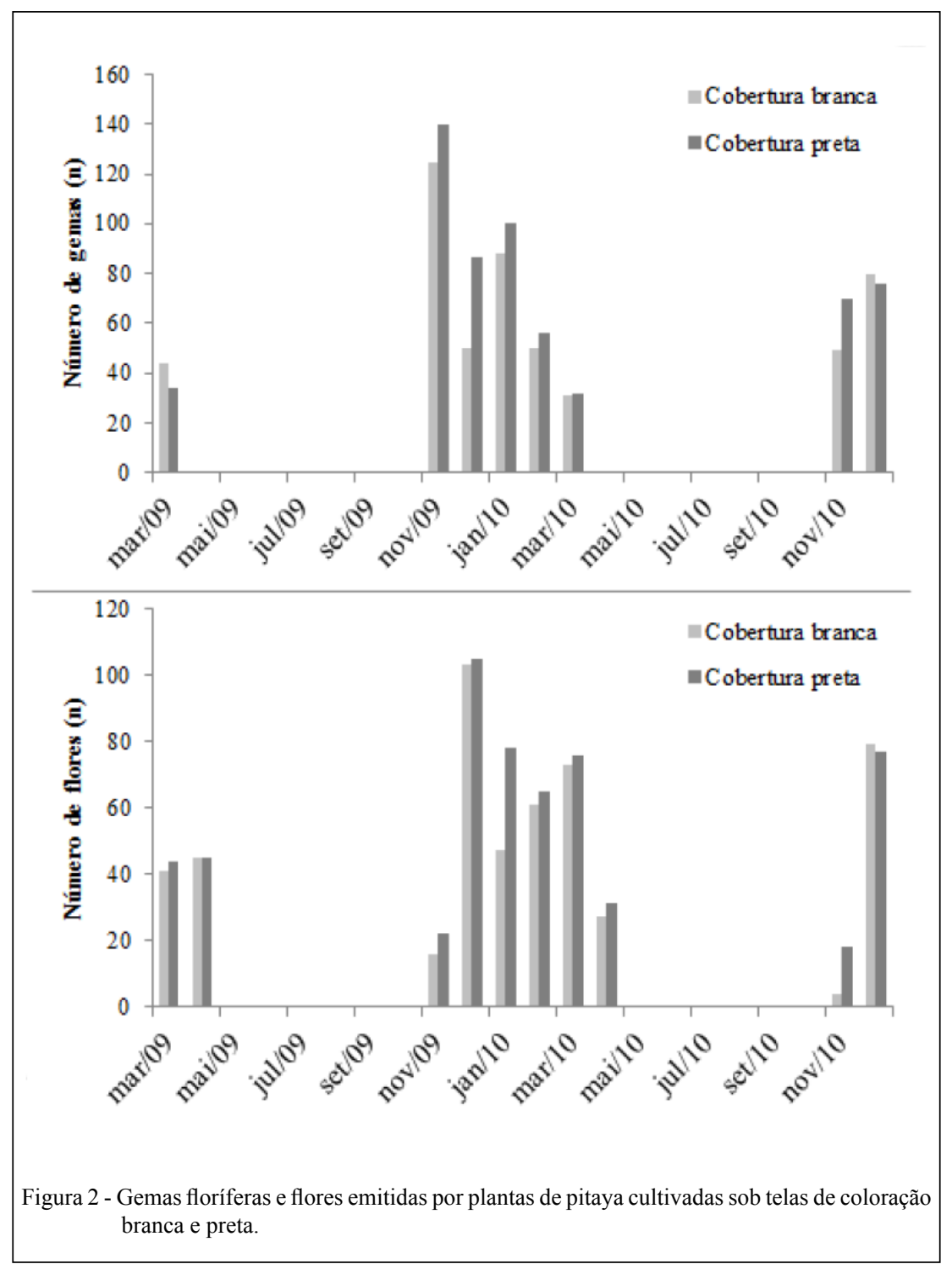

Ciência Rural, v.45, n.4, abr, 2015. 
aumento da temperatura, que pode influenciar no florescimento. Dessa forma, a coloração da tela pode afetar diretamente o microclima, influenciando o desenvolvimento das plantas. A colheita, durante o período avaliado, variou de 34 a 43 dias. Sete dias após a polinização, é possível verificar se a flor foi ou não fertilizada. Caso haja fertilização, o ovário permanece verde e inicia seu desenvolvimento, aumentando em diâmetro. Em flores onde não houve o pegamento do fruto, o ovário amarelece e murcha, caindo alguns dias depois. Para frutos cuja polinização ocorreu no mês de março, a maturação ocorreu cerca de 36 dias após a polinização, enquanto que frutos obtidos a partir de polinização no mês de abril tiveram um desenvolvimento mais vagaroso, estando aptos para a colheita com cerca de 42 dias. Segundo CASTILLO \& ORTIZ (1994) e WEISS et al. (1994) o tempo requerido para o desenvolvimento dos frutos, da antese à colheita, é de 39 a 52 dias. MARQUES et al. (2011) observaram que, em Lavras, o tempo decorrido para o desenvolvimento do fruto é de 30 a 40 dias após a abertura da flor.

CENTURIÓN et al. (2008), avaliando o desenvolvimento de frutos de $\boldsymbol{H}$. undatus no México, observaram que a maturação ocorreu entre 25 e 31 dias após a antese, com temperatura média e precipitação de $26,1^{\circ} \mathrm{C}$ e $73,9 \mathrm{~mm}$, respectivamente, durante o período de avaliação. Em Israel, 30 a 35 dias decorrem da antese à coloração completa do fruto, quando temperaturas diárias são de $25^{\circ} \mathrm{C}$, mas de 40-45 dias são requeridos quando a temperatura diária média é de $20^{\circ} \mathrm{C}$ (NERD et al., 1999). Assim, é possível inferir que o desenvolvimento dos frutos de pitaya vermelha é dependente diretamente das condições do local de cultivo (temperatura e precipitação), sendo menor sua duração em condições de maior temperatura e precipitação. No primeiro ciclo, a temperatura média foi de $22,9^{\circ} \mathrm{C}$, e $201,8 \mathrm{~mm}$ de precipitação, enquanto, no segundo ciclo, foi de $21,1^{\circ} \mathrm{C}$ e $95,5 \mathrm{~mm}$.

O tempo total entre o aparecimento do botão floral até a colheita pode levar entre 52 a 66 dias. Este período parece ser dependente do local da cultura, uma vez que, no Sri Lanka, PUSHPAKUMARA et al. (2005) afirmam que o período da emissão do botão floral até a colheita pode variar entre 60 e 70 dias, enquanto que, em Lavras, este período foi um pouco menor, de 50 a 60 dias (MARQUES et al., 2011).

\section{CONCLUSÃO}

Pode-se observar a ocorrência de nove fluxos floríferos, com início de emissão de gemas no mês de novembro e pico de florescimento no mês de dezembro, sendo que altas temperaturas e início da estação chuvosa estão associados ao início da emissão das gemas reprodutivas.

Da emissão das gemas até a antese, tem-se de 18 a 23 dias, enquanto, da antese à colheita, de 34 a 43 dias. O tempo total do aparecimento do botão floral até a colheita é de 52 a 66 dias. A coloração de cobertura plástica influencia no total de flores.

\section{AGRADECIMENTOS}

À Fundação de Amparo à Pesquisa do Estado de São Paulo (FAPESP), pela concessão de bolsa de mestrado à primeira autora (Processo 2008/56615-5).

\section{REFERÊNCIAS}

BASTOS, D.C. et al. Propagação da Pitaya Vermelha por estaquia. Ciência e Agrotecnologia, Lavras, v.30, n.6, p.1106-1109, 2006. Disponível em: <http://www.scielo.br/scielo.php?pid=S141370542006000600009\&script $=$ sci_arttext $>$. Acesso em: 25 set. 2014. doi: 10.1590/S1413-70542006000600009.

BEZERRA NETO, F. et al. Sombreamento para produção de mudas de alface em alta temperatura e ampla luminosidade. Horticultura Brasileira, Brasília, v.23, n.1, p.133-137, 2005. Disponível em: $<$ http://www.scielo.br/scielo.php?script=sci_artte

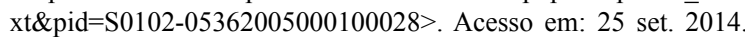
doi: $10.1590 / \mathrm{S} 0102-05362005000100028$.

CASTILLO, M.R.; ORTIZ, Y.D.H. Floración y fructificación de pitajaya em Zaachila, Oaxaca. Revista Fitotecnia Mexicana, Chapingo, v.17, p.12-19, 1994.

CENTURIÓN, Y.A. et al. Cambios físicos, químicos e sensoriales en frutos de pitahaya (Hylocereus undatus) durante su desarrolo. Revista Fitotecnia Mexicana, Chapingo, v.31, n.1, p.1-5, 2008. Disponível em: <http://www.revistafitotecniamexicana.org/ documentos/31-1/1a.pdf>. Acesso em: 25 set. 2014.

EMPRESA BRASILEIRA DE PESQUISA AGROPECUÁRIA - EMBRAPA. Sistema brasileiro de classificação de solos. Brasília, 1999. 412p.

GARCÍA-SUÁREZ, F. et al. Pitaya (Stenocereus stellatus) fruit growth is associated to wet season in Mexican dry tropic. Pyton, Vicente López, v.76, p.19-26, 2007. Disponível em: $<$ http://www.scielo.org.ar/scielo.php?script=sci_arttext\&pid $=$ S1851-56572007000100002>. Acesso em: 25 set. 2014 .

LE BELLEC, F. et al. Pitahaya (Hylocereus spp.): a new crop, a market with a future. Fruits, Paris, v.61, n.4, p.237-250, 2006. Disponível em: <http://journals.cambridge.org/download.php?file =\%2FFRU\%2FFRU61_04\%2FS0248129406000211a.pdf\&code= 43f8e5939236678e9ea5e022a6df2e32>. Acesso em: 25 set. 2014. doi: $10.1051 /$ fruits:2006021.

MERTEN, S. A review of Hylocereus production in the United States. Journal of the Professional Association for Cactus Development, California, v.5, p.98-105, 2003. Disponível em: <http://www.jpacd. org/downloads/vol5/v5p98-105.pdf>. Acesso em: 25 set. 2014. 
MARQUES, V.B. et al. Fenologia reprodutiva de pitaia vermelha no município de Lavras, MG. Ciência Rural, Santa Maria, v.41, n.6, p.984-987, 2011. Disponível em: <http://www.scielo.br/ scielo.php?script=sci arttext\&pid=S0103-84782011000600011>. Acesso em: 25 set. 2014. doi: 10.1590/S0103-84782011005000071.

MARQUES, V.B. et al. Ocorrência de insetos na pitaia no município de Lavras-MG. Revista Agrarian, Dourados, v.15, n.5, p.88-92, 2012. Disponível em: < http://www.periodicos.ufgd.edu. br/index.php/agrarian/article/viewFile/1116/1020>. Acesso em: 25 set. 2014.

MARO, L.A.C. et al. Ciclo de produção de cultivares de framboeseiras (Rubus idaeus) submetidas à poda drástica nas condições do sul de Minas Gerais. Revista Brasileira de Fruticultura, v.34, n.2, p.435-441, 2012. Disponível em: $<$ http://www.scielo.br/scielo.php?script=sci_arttext\&pid $=$ S0100-29452012000200016 $>$. Acesso em: 25 set. 2014. doi: $10.1590 / \mathrm{S} 0100-29452012000200016$

MIZRAHI, Y.; NERD, A. Climbing and columnar cacti: new arid lands fruit crops. In: JANICK, J. (Ed.). Perspective in new crops and new crops uses. Alexandria: ASHS, 1999. p.358-366.

NERD, A.; MIZRAHI, Y. Fruit development and ripening in yellow pitaya. Journal of the American Society for Horticultural Science, Alexandria, v.123, p.560-562, 1998. Disponível em: $<\mathrm{http}$ ://journal.ashspublications.org/content/123/4/560.full.pdf $>$. Acesso em: 25 set. 2014.

NERD, A. et al. High Summer temperatures inhibit flowering in vine pitaya crops (Hylocereus spp.). Scientia Horticulturae, Amsterdam, v.96, p.323-350, 2002. Disponível em: <http://www. sciencedirect.com/science/article/pii/S0304423802000936>. Acesso em: 25 set. 2014. doi: 10.1016/S0304-4238(02)00093-6.

OLIVEIRA, M.C. et al. Características fenológicas e físicas e perfil de ácidos graxos em oliveiras no sul de Minas Gerais. Pesquisa Agropecuária Brasileira, Brasília, v.47, n.1, p.3035, 2012. Disponível em: <http://www.scielo.br/scielo. php? script $=$ sci_arttext\&pid $=$ S0100-204X2012000100005\&ln $\mathrm{g}=\mathrm{pt} \& \mathrm{nrm}=\mathrm{is}>$. Acesso em: 25 set. 2014. doi: 10.1590/S0100204X2012000100005.
PUSHPAKUMARA, D. et al. Flowering and fruiting phenology, pollination vectors and breeding system of dragon fruit (Hylocereus spp.). Sri Lankan Journal of Agricultural Sciences, Sri Lanka, v.42, p.81-91, 2005

RAVEH, E. et al. Pitayas (Genus Hylocereus): a new fruit crop for the Negev Desert of Israel. In: JANICK, J.; SIMON, J.E. (Eds.). News crops. New York: Wiley, 1993. Cap.13, p.491-495.

RAVEH, E. et al. Responses of two hemiepiphytic fruit crop cacti to different degrees of shade. Scientia Horticulturae, Amsterdam, v.73, p.151-164, 1998. Disponível em: < http://www.sciencedirect. com/science/article/pii/S0304423897001349>. Acesso em: 25 set. 2014. doi: 10.1016/S0304-4238(97)00134-9.

RUIZ, A. et al. Estudio fenológico de cactáceas en el Enclave Seco de La Tatacoa, Colombia. Biotropica, Malden, v.32, n.3, p.39-407, 2000. Disponível em: <http://onlinelibrary.wiley.com/ doi/10.1111/j.1744-7429.2000.tb00486.x/pdf>. Acesso em: 25 set. 2014. doi: 10.1111/j.1744-7429.2000.tb00486.x.

SEGANTINI, D.M. et al. Fenologia da figueira-da-índia em Selvíria-MS. Revista Brasileira de Fruticultura, Jaboticabal, v.32, n.2, p.630-636, 2010. Disponível em: <http://www.scielo.br/ scielo.php?script=sci_arttext\&pid=S0100-29452010000200038>. Acesso em: 25 set. 2014. doi: 10.1590/S0100-29452010005000049.

TAIZ, L. ZEIGER, E. Fisiologia Vegetal. 4. ed. Porto Alegre: Artmed, 2009. 722 p.

VALIENTE-BANUET, A. et al. Pollination biology of the hemiepiphytic cactus Hylocereus undatus in the Tehuacán Valley, Mexico. Journal of Arid Environments, Londres, v.68, p.1-8, 2007. Disponível em: <http://www.sciencedirect.com/science/ article/pii/S0140196306001406>. Acesso em: 25 set. 2014. doi: 10.1016/j.jaridenv.2006.04.001.

WEISS, J. et al. Flowering behavior and pollination requirementes in climbing cacti with fruit crop potential. HortScience, Alexandria, v.29, p.1487-1492, 1994. Disponível em: $\quad<$ http://hortsci.ashspublications.org/content/29/12/1487.full. pdf $>$. Acesso em: 25 set. 2014. 